TITLE:

\title{
An experimental study on the oblique collisions of water droplets with a smooth hot solid
}

\section{$\operatorname{AUTHOR}(S):$}

Fujimoto, Hitoshi; Doi, Ryota; Takuda, Hirohiko

\section{CITATION:}

Fujimoto, Hitoshi ... [et al]. An experimental study on the oblique collisions of water droplets with a smooth hot solid. Journal of Fluids Engineering 2012, 134(7): 071301.

\section{ISSUE DATE:}

2012-06-21

URL:

http://hdl.handle.net/2433/237614

\section{RIGHT:}

Copyright (c) 2011 by ASME. This manuscript version is made available under the CC-BY-NC-ND 4.0 license

http://creativecommons.org/licenses/by-nc-nd/4.0/; The full-text file will be made open to the public on 21 June 2013 in accordance with publisher's 'Terms and Conditions for Self-Archiving'.; この論文は出版社版でありません。引用の際 には出版社版をご確認ご利用ください。; This is not the published version. Please cite only the published version. 


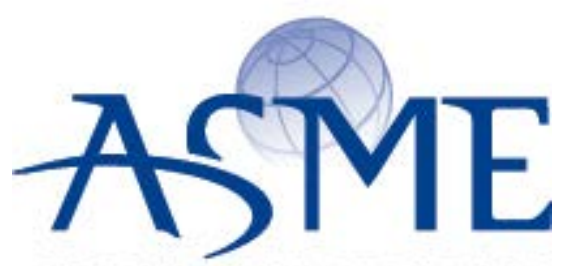

\section{American Society of Mechanical Engineers}

SETTING THE STANDARD

\section{ASME Accepted Manuscript Repository}

\section{Institutional Repository Cover Sheet}

ASME Paper Title: An Experimental Study on the Oblique Collisions of Water Droplets With a Smooth Hot Solid

Authors: $\quad$ Hitoshi Fujimoto, Ryota Doi , Hirohiko Takuda

ASME Journal Title: Journal of Fluids Engineering

Volume/Issue Volume 134 / Issue 7

Date of Publication (VOR* Online) June 21, 2012

ASME Digital Collection URL: http://fluidsengineering.asmedigitalcollection.asme.org/article.aspx?articleid=144094

DOI:

*VOR (version of record)

http://fluidsengineering.asmedigitalcollection.asme.org/data/journals/jfega4/27539/071301_1.pdf 


\section{An Experimental Study on the Oblique Collisions of Water Droplets With a Smooth Hot Solid}

Hitoshi FUJIMOTO, Ryota DOI, and Hirohiko TAKUDA

Graduate School of Energy Science, Kyoto University, Kyoto 606-8501, Japan

\section{ABSTRACT}

[Background] The motions of liquid droplets impinging on a solid substrate have been studied experimentally in fundamental research on various types of industrial applications, including spray cooling.

[Method of Approach] The oblique collision of a single water droplet with a hot Inconel 625 alloy surface has been investigated by means of a two-directional flash photography technique that uses two digital still cameras and three flash units. The experiments were conducted under the following conditions. The pre-impact diameter of the droplets was approximately $0.6 \mathrm{~mm}$; the impact velocity was $1.9-3.1 \mathrm{~m} / \mathrm{s}$; and the temperature of the Inconel 625 alloy surface ranged from $170{ }^{\circ} \mathrm{C}$ to $500{ }^{\circ} \mathrm{C}$. The impact angle of droplets on the solid surface was in the range $45^{\circ}-90^{\circ}$. Experiments using 2.5 $\mathrm{mm}$ diameter droplets at an impact velocity of $0.84-1.4 \mathrm{~m} / \mathrm{s}$ were also conducted at the surface temperature of $500{ }^{\circ} \mathrm{C}$.

[Results] At surface temperatures of $200{ }^{\circ} \mathrm{C}, 300{ }^{\circ} \mathrm{C}$, and $400^{\circ} \mathrm{C}$, the droplet deforms into an asymmetric shape and moves downward along the tilted surface. Numerous secondary droplets jet upward from the deforming droplet as a result of the blowout of vapor bubbles into the atmosphere. At a surface temperature of $500{ }^{\circ} \mathrm{C}$ and a low Weber number, $W e_{n}$, based on the normal velocity component to the solid surface, no secondary droplets are observed. The droplet rebounds off the solid without disintegrating. The droplet becomes almost axisymmetric in shape during the collision regardless of the impact angle.

[Conclusions] The dimensionless collision behaviors of large and small droplets were similar for the same $W e_{n}$ when the temperature was $500{ }^{\circ} \mathrm{C}$. Using $W e_{n}$, we investigated the deformation characteristics of droplets in oblique collisions.

Keywords: Oblique collision, Weber number, Two-directional flash photography, Dynamical similarity, Droplet 


\section{INTRODUCTION}

For many decades, the motions of liquid droplets impinging on a solid substrate have been studied experimentally in fundamental research on various types of industrial applications [1-3]. When a spherical droplet impacts a hot solid at a temperature higher than the saturation temperature of the liquid, boiling incipience occurs at the liquid/solid interface, and vapor bubbles are generated inside the droplet. Such boiling phenomena are strongly dependent on the temperature of the solid surface. If the temperature is relatively low, the bubble nucleation is weak, and the liquid comes in direct contact with the solid during the collision. Boiling becomes appreciable with an increase in interfacial temperature, and the probability of liquid/solid contact decreases.

At interfacial temperatures above the superheat limit of a liquid [4,5], liquid/solid direct contact occurs very rarely. A vapor film is formed between the liquid and the solid immediately after droplet impact [6]. As a consequence, the droplet is insulated from the solid through the vapor layer. In such cases, the Weber number is a key factor in the deformation mechanics of the droplet [1-3,7]. The Weber number is the ratio of the inertia force to the surface tension force. It is given as follows:

$$
W e=\frac{\rho v^{2} d_{p}}{\sigma},
$$

where $\rho, v, d_{p}$, and $\sigma$ denote the liquid density, droplet impact velocity, pre-impact droplet diameter, and surface tension, respectively. If the Weber number is small, the droplet impacts a hot solid, deforms into a circular disk, recoils (owing to the effect of surface tension), and eventually rebounds off the solid surface. For large Weber numbers, the droplet splits into many small droplets during collision. The critical boundary at which the disintegration of droplets occurs has been discussed in relation to the Weber number [7]. Further, the maximum diameter of spreading droplets, the time required for the circular water film to reach the maximum spreading diameter, and the droplet resident time on a hot surface have been correlated via functions of the Weber number [8-12]. The predictions are in moderate agreement with experiments.

Besides the temperature of the solid and the Weber number, the impact angle of droplets on the solid surface also influences the deformation behavior of droplets. When a droplet impacts a surface obliquely, it contains non-zero velocity components along the solid surface; therefore, the characteristics of dynamic behavior may substantially differ from those of the normal impacting droplets. We conducted a brief literary study because our present investigations deal with the oblique collisions of droplets with solids. Karl and Frohn [11] studied the deformation processes of water and ethanol droplets of $0.07-0.26 \mathrm{~mm}$ in diameter impacting obliquely onto chromium-plated copper or steel surfaces heated above the Leidenfrost temperature. They found a correlation between the non-dimensional maximum droplet deformation in collisions and the Weber number, $W e_{n}$, based on the normal velocity component. Chen et al. [12] investigated the impact of 0.50-0.95 mm diameter diesel drops impinging onto an inclined stainless-steel surface at $480{ }^{\circ} \mathrm{C}$. They proposed a correlation 
between the non-dimensional maximum spread and $W e_{n}$.

Kang and Lee [13] studied the impact of $2.3 \mathrm{~mm}$ diameter water droplets on a heated copper surface at $125-280^{\circ} \mathrm{C}$. They used a high-speed camera to determine the effects of varying their impact angles on their deformation behavior. By using a high spatial resolution CCD camera, Šikalo et al. [14] investigated the dynamics of the collisions of water, isopropanol, and glycerin droplets having diameters ranging from 1.8 to $3.3 \mathrm{~mm}$. Their investigation was conducted with low $W e_{n}$ and low-impact angles of room-temperature dry walls and liquid films. They presented a correlation for the size of the secondary droplet. In addition, they quantified the critical impact angle at which rebounding first occurred in terms of the $W e_{n}$.

Ko and Chung [15] conducted experiments to investigate the break-up of $n$-decane droplets having approximately $0.3-0.5 \mathrm{~mm}$ diameters impinging on a hot brass surface. They clarified the effect of the wall temperature, impinging velocity, droplet diameter, and impinging angle on the break-up probability. Moreira et al. [16] addressed an experimental study of the secondary atomization of 2.75 mm diameter water drops and $2.53 \mathrm{~mm}$ diameter isooctane drops impinging on tilted heated stainless surfaces. Castanet et al. [17] presented the results of an experimental investigation of oblique impacts of water droplets onto a smooth heated nickel plate. The droplet temperature was measured using two-color laser-induced fluorescence thermometry. The change in droplet temperature during an impact was found to depend on the normal velocity; however, the change in droplet temperature was independent of the wall temperature when this temperature exceeded the Leidenfrost temperature.

Kang and Ng [18] observed the spreading behavior of individual splats caused by 0.005 to 0.040 mm diameter droplets impacting at different substrate inclinations; they quantified their findings using the spread factor and aspect ratio. Anders et al. [19] studied the droplet wall interaction of 0.09-0.21 mm diameter ethanol droplets impacting obliquely onto a heated chromium-plated solid surface. They also investigated the effects of the impact velocity on the collision dynamics.

In most of the previous experimental studies, the collision behavior of droplets was investigated using only one camera. Because the motion of droplets is three-dimensional by nature, the detailed mechanics of oblique collisions remain unclear. Multidirectional observations using more than one camera are required for a detailed understanding of three-dimensional phenomena in oblique collisions.

The present authors [6] studied the deformation process of water droplets impacting normally onto an Inconel alloy surface heated to $170-500^{\circ} \mathrm{C}$ through a two-directional flash photography technique that uses two digital still cameras and three flash units. Experiments were conducted using droplets of two different drop diameters of approximately $0.6 \mathrm{~mm}$ and $2.5 \mathrm{~mm}$. The similarities/differences between the motions of a small droplet and a large one were investigated on the basis of the Weber number of the droplets. Direct qualitative and quantitative comparisons of the collisions of the large and small droplets were carried out for a fixed temperature of a solid surface, a fixed Weber number, and fixed combination of liquid/solid materials. The dynamical similarity between the liquid motions of large and small droplets was roughly obtained for the temperatures of $500{ }^{\circ} \mathrm{C}$, but not for 
170-300 ${ }^{\circ} \mathrm{C}$. Moreover, it was found that the measurement technique was suitable for observing the three-dimensional nature of flow.

In the present study, the oblique collision of two different-sized droplets with a hot solid is investigated using the same experimental setup and observation techniques described in our previous article [6]. The objective is to improve our understanding of the physics governing the phenomena of oblique collisions. First, the oblique collision phenomena of small droplets with a solid are studied to investigate the effect of varying the solid temperature. Second, the differences/similarities between the motions of the small and large droplets are studied in detail under fixed Weber number conditions at $500{ }^{\circ} \mathrm{C}$. Finally, deformation behaviors of droplets at $500{ }^{\circ} \mathrm{C}$ in normal and oblique collisions are discussed in terms of the Weber number based on the normal velocity component.

\section{EXPERIMENTS}

\section{A. Experimental apparatus}

Figure 1 is a schematic of the experimental setup for observing the collision behavior of small droplets. Because the experimental setup and observation techniques are very similar to those of our prior study [6], they are only briefly explained here. The setup consists of a nozzle unit to form a stream of uniform-sized droplets, a rotating disk with a slit hole to isolate a single droplet per revolution, a test piece on which droplets impinge, a copper base embedded in an electric heater, two digital cameras, and three strobe lights. These components were set on an optical table equipped with a vibration isolator. The test liquid is distilled water at room temperature. The pre-impact diameter, $d_{p}$ of the droplets is approximately $0.6 \mathrm{~mm}$. The impact velocity, $v$, can be adjusted by varying the air pressure in the reservoir. For observing the collision behavior of large droplets, the rotating disk unit was removed. Droplets with diameters of approximately $2.5 \mathrm{~mm}$ are formed by supplying a small amount of water to the nozzle unit. The impact velocity can be adjusted by varying the nozzle-to-substrate distance.

The test piece was made of Inconel alloy 625 whose arithmetic mean surface roughness was less than $0.3 \mu \mathrm{m}$. The surface roughness is negligibly small compared to the droplet size as well as the measurement accuracy as explained later. The test piece is mounted on a copper base with an embedded electric heater. The surface temperature of the solid is maintained at a preset value using K-type thermocouples and a temperature controller that regulates the electric power supply to the heater. The deviation from the preset temperature during the experiments was within $\pm 10{ }^{\circ} \mathrm{C}$. The solid surface can be heated up to $500{ }^{\circ} \mathrm{C}$. The copper base with a test piece is installed on a positioning stage, which can adjust the vertical position and the tilt angle. The test piece was tilted at various angles $(\alpha)$ from $0^{\circ}$ to $45^{\circ}$ from the horizontal, as shown in Fig. 2.

\section{B. Photography and measurement procedure}


A schematic layout of the flash photography setup is shown in Fig. 2. The setup is composed of two digital still cameras with an effective spatial resolution of $3888 \times 2592$ pixels, three strobe lights, and a flash controller. Two types of optical systems are aligned. For camera A in the figure, a digital camera with a macro lens, the test piece, and a pair of strobe lights are set in a horizontal line to take double-exposure backlit images of the droplets. For camera B, a digital camera and a strobe light are used to take droplet images from an overhead view. These strobe lights could be independently triggered by a flash controller with a time resolution of $1 \mu \mathrm{s}$. The droplet images are exposed only when the flash units are triggered. The duration of flashes is less than $2 \mu$ s. All optical components are mounted on positioning stages. The tilt angle of camera B can be easily adjusted with a tilt stage. Many instantaneous images of droplets are taken by the photographic system under the same experimental conditions with different flash timings. These images are arranged in chronological order so that the three-dimensional motion of droplets could be followed.

Figure 3 shows examples of double-exposed images of the droplets taken by camera A. The tilt angle is $\alpha=30^{\circ}$. The time intervals between the two flashes were (a) $0.6 \mathrm{~ms}$ and (b) $1.2 \mathrm{~ms}$. Note that one flash bulb was colored red so that the images of the droplets exposed at the first and second flashes could be easily distinguished. In (a), the time interval between the two flashes is small. Neither droplet has reached the solid surface even after the second flash. The pre-impact diameter of each droplet, $d_{P}$, was determined directly from the images of the droplet by using image analyzing software. The impact velocity of the droplet, $v$, was also determined from the time interval, $\Delta t$, between the two flashes and the distance, $\Delta L$, moved by the droplet:

$$
v=\frac{\Delta L}{\Delta t} \text {. }
$$

In addition, the uncertainty in the measurement of the spatial length, which depends on the magnification of the lens system, was within $\pm 3 \mu \mathrm{m}$ for the cases of small droplets. In (b), the first flash was triggered before the impact of the droplet, and the second flash was activated after the impact. The elapsed time $t_{e}$ after the droplet impact can be determined from the spacing, $\Delta L_{w}$ between the bottom of the droplet and the solid at the first flash, the impact velocity, and the time interval as follows:

$$
t_{e}=\Delta t-\frac{\Delta L_{w}}{v}+\frac{d_{p}}{2 v} \frac{1-\cos \alpha}{\cos \alpha} .
$$

The droplet diameter and spacing were measured for every image, and irregular data were removed to minimize experimental uncertainties.

Figure 4 describes the coordinate system. The origin of the coordinate is chosen as the impact point. The $x$ axis is taken downward along the solid surface. In the present study, some dimensionless parameters are introduced to discuss the similarity of droplet motion. The spatial scale is normalized 
by the pre-impact diameter of the droplet. The dimensionless time based on the normal velocity component is given by

$$
\tau_{n}=\frac{t_{e}(v \cos \alpha)}{d_{p}}
$$

In addition, the Weber number based on the normal velocity component is defined by

$$
W e_{n}=\frac{\rho(v \cos \alpha)^{2} d_{p}}{\sigma}=W e \cos ^{2} \alpha
$$

Note that $W e_{n}=W e$ is true for a normal collision $\left(\alpha=0^{\circ}\right)$.

Experimental conditions are listed in Table 1. It should be noted that $T_{i}$ presents the estimated interfacial temperature at the moment of droplet impact as described in a later subsection. In the present study, first, the effect of varying temperature of the solid on the motion of the droplet was investigated using small droplets $\left(d_{p} \approx 0.6 \mathrm{~mm}\right)$ at the tilt of angle $\alpha=30^{\circ}$ at low $W e_{n}$ numbers. The temperature of the solid surface varied from $T_{w}=170{ }^{\circ} \mathrm{C}$ to $500{ }^{\circ} \mathrm{C}$. Second, the experiments using small droplets and large droplets $\left(d_{p} \approx 2.5 \mathrm{~mm}\right)$ were conducted with the temperature of solid $T_{w}=$ $500{ }^{\circ} \mathrm{C}$ to study the dynamic similarity of droplet motion under a fixed Weber number. Furthermore, the deformation behaviors of droplets at $500{ }^{\circ} \mathrm{C}$ in normal and oblique collisions were observed to determine the effect of $W e_{n}$.

\section{Estimation of the interfacial temperature}

The temperature at the liquid/solid interface is a key factor in the boiling phenomena. It is, however, difficult to measure the temperature accurately. In the present study, the temperature at the liquid/solid interface at the moment of impact is estimated with a simple one-dimensional theory for interfacial contact between two semi-infinite solids at different temperatures [20-26]. The interfacial temperature, $T_{i}$, is given by $[27,28]$

$$
T_{i}=\frac{T_{H} \sqrt{\rho_{H} C_{P H} \lambda_{H}}+T_{C} \sqrt{\rho_{C} C_{P C} \lambda_{C}}}{\sqrt{\rho_{H} C_{P H} \lambda_{H}}+\sqrt{\rho_{C} C_{P C} \lambda_{C}}},
$$

where $\left(T_{C}, T_{H}\right),\left(\rho_{C}, \rho_{H}\right),\left(C_{P C}, C_{P H}\right)$, and $\left(\lambda_{C}, \lambda_{H}\right)$ are the temperatures, densities, specific heats, and thermal conductivities, respectively, of the two materials $C$ and $H$. According to Eq. (6), this theory indicates that the interfacial temperature is independent of the time elapsed after contact between the 
two materials. In reality, however, the interfacial temperature decreases with time because of convection, phase changes, and axisymmetric/three-dimensional heat transfer. Therefore, Eq. (6) can be used for rough evaluations of the interfacial temperature at the moment of droplet impact.

According to the literature [4,5,29-35], the limit of superheat of water $\left(T_{h n}\right)$ at atmospheric pressure lies in the $283-313{ }^{\circ} \mathrm{C}$ range, and the critical temperature of water is $374{ }^{\circ} \mathrm{C}$. If the calculated interfacial temperature becomes higher than the limit of superheat, the temperature calculated by Eq. (6) has no physical meaning. In such a case, a vapor film is formed between the liquid and solid immediately after droplet impact. The interfacial temperature calculated by Eq. (6) is listed in Table 1. For $T_{w}=400{ }^{\circ} \mathrm{C}$ and $500{ }^{\circ} \mathrm{C}$, the interfacial temperatures are higher than $T_{h n}$; therefore, it is assumed that a vapor film is formed immediately after the droplet impact. Although the time required for forming vapor layers cannot be measured correctly, it must be very short compared to the characteristic time scales $\left(d_{p} / v\right)$ in the present experiments [33].

\section{RESULTS AND DISCUSSION}

A. Effects of varying the solid surface temperature

Figure 5 shows the deformation behavior of a water droplet on the inclined surface at $d_{p}=0.61 \pm$ $0.01 \mathrm{~mm}, v=2.1 \pm 0.05 \mathrm{~m} / \mathrm{s}, T_{w}=170 \pm 10^{\circ} \mathrm{C}$, and $\alpha=30^{\circ}$. The interfacial temperature calculated by Eq. (6) is $T_{i}=141^{\circ} \mathrm{C}$. The corresponding Weber number, We $e_{n}$, defined by Eq. (5) is 28. The backlit images of droplets taken by camera A are presented in (a). The images taken by camera $\mathrm{B}$ from a bird's-eye view are shown in (b). The elapsed time, $t_{e}$, is presented in each image. Note that the upper part of the images in (b) corresponds with the uphill side of the solid surface. After the collision, a thin circular liquid film was formed around the bottom of the droplet body. At $t_{e}=0.07$ ms in (b), a single bubble (indicated by a circle) was observed at the impact point. Subsequently, additional bubbles were seen around the single bubble at $t_{e}=0.16 \mathrm{~ms}$; this is also indicated by a circle. These bubbles were probably caused by the entrapment of air [36]. The liquid film spread radially with time, whereas the droplet height decreased. Thus, the droplet deformed into a circular thin disk. Most of the liquid moved to the downhill side owing to the impact inertia, but the bubbles remained near the impact point in (b) $\left(t_{e}=0.07-0.52 \mathrm{~ms}\right)$.

In the horizontal direction, the droplet spread to its maximum extension at $t_{e} \sim 0.52 \mathrm{~m}$ after which liquid constriction commenced. During the constricting process $\left(t_{e}=0.70-1.18 \mathrm{~ms}\right.$ ), the liquid film in the lower side (leading edge side; see Fig. 4 ) became prominent ( $t_{e}=1.18$ and $1.51 \mathrm{~ms}$ ). The liquid film on the upper side was very thin and eventually vanished. The droplet deformed into a dome-shaped mass. Subsequently, a few bubbles were observed in the liquid. These were formed because of boiling, air entrapment at the moment of droplet impact, or the deposition of dissolved air in the liquid.

Figure 6 shows the experimental results for $T_{w}=200 \pm 10^{\circ} \mathrm{C}\left(T_{i}=167{ }^{\circ} \mathrm{C}\right)$. Unlike the previous case, many boiling bubbles were seen in the liquid during the collision. Moreover, numerous small 
droplets were observed above the body of the droplet after $t_{e}=0.21 \mathrm{~ms}$; these will hereafter be called "secondary droplets." The formation of secondary droplets can be explained by the following mechanism. At the liquid/solid interface, the boiling vapor bubbles grow in size with time, whereas the droplet deforms into a thin circular disk. As a consequence, the upper sides of the vapor bubbles reach the free liquid surface (the liquid/atmospheric-air interface) and then blow out to the atmosphere; they are accompanied by many secondary droplets flying upward. Obviously, bubble blowout occurs in the thin liquid film region. The liquid moves to the downhill side with time and is always in direct contact with the solid surface. The central part of the liquid is relatively smooth at $t_{e}$ $=0.28-0.55 \mathrm{~ms}$, whereas the part around it is lumpy. Therefore, the secondary droplets are mainly jetted from the thin film part. At $t_{e}=0.70-1.09 \mathrm{~ms}$, secondary droplets are jetted from all areas of the liquid and larger secondary droplets appear. At $t_{e}=2.91 \mathrm{~ms}$, part of the liquid is separated from the solid surface, but some liquid continues to be in direct contact with the solid surface.

Figure 7 indicates the collision behavior of a water droplet on the hot surface at $T_{w}=300 \pm 10{ }^{\circ} \mathrm{C}$ $\left(T_{i}=251{ }^{\circ} \mathrm{C}\right.$ ). The generation of secondary droplets is seen after $t_{e}=0.37 \mathrm{~ms}$, as shown in (a), but they are smaller in number than in the case of Fig. 6. The apparent liquid/solid contact area decreases with time ( $t_{e}=0.37-1.26 \mathrm{~ms}$ ), suggesting that direct liquid/solid contact is dramatically reduced by the presence of the vapor bubbles or a thin vapor film at the liquid/solid interface. Thereafter, the liquid moves in a radially inward direction to the downhill side with time. Eventually, all of the liquid becomes separated from the solid surface (at $t_{e}=1.93 \mathrm{~ms}$ ).

Figure 8 shows the results for $T_{w}=400 \pm 10^{\circ} \mathrm{C}$. The estimated interfacial temperature is $T_{i}=$ $338^{\circ} \mathrm{C}$, which is a little above the superheat limit of water at atmospheric pressure $\left(\sim 300^{\circ} \mathrm{C}\right)[4,5]$. At $t_{e}=0.13$ and $0.19 \mathrm{~ms}$ in (b), the liquid/solid interface appears hazy, suggesting that a vapor film was probably formed between the liquid and the solid surface immediately after droplet impact. The interfacial temperature decreased owing to convection and was soon below the superheat limit. The vapor layer was easily broken because of impact inertia, and rewetting occurred at the liquid/solid contact. This resulted in the formation of vapor bubbles at the solid surface. At $t_{e}=0.49 \mathrm{~ms}$, secondary droplets formed near the impact point, as shown in (a). Owing to local breakage of the liquid film, a dry area appeared at the center at $t_{e}=0.62-0.68 \mathrm{~ms}$, as indicated in the figure by an arrow. The secondary droplets decreased in number owing to a reduction in the liquid/solid contact area. The dry area vanished at $t_{e}=0.87 \mathrm{~ms}$. At $t_{e}=1.24 \mathrm{~ms}$, the droplet was elongated in the direction normal to the solid surface. At $t_{e}=1.64 \mathrm{~ms}$, all of the liquid becomes separated from the solid surface. As expected, the droplet slipped down the surface with time.

Figure 9 shows the results for $T_{w}=500 \pm 10{ }^{\circ} \mathrm{C}$. The estimated interfacial temperature is $T_{i}=$ $426^{\circ} \mathrm{C}$, which is higher than the critical temperature of water $\left(374{ }^{\circ} \mathrm{C}\right)$. Note that the dimensionless time based on the normal velocity component, $\tau_{n}$, is presented in parentheses in the images. After the collision, the droplet spreads radially. The liquid film reaches its maximum extension (at $t_{e}=$ $0.36-0.47 \mathrm{~ms}$ ) and then constricts. At $t_{e}=0.79-1.68 \mathrm{~ms}$, the liquid is elongated upward in the shape of a bowling pin and rebounds off the heated surface. The liquid/solid interface appears consistently 
hazy, suggesting that a vapor film was continuously formed between the liquid and the solid. The quantitative measurement of vapor film is beneficial for better understanding of the collision phenomena of droplets, although it was experimentally difficult. This remains a challenge for future work.

Unlike in the case of lower temperatures, no secondary droplets were observed in the entire deformation process, as shown in (a). The deformation process of the droplet is very similar to the process for normal collisions. In addition, the point at which the droplet rebounds off is located downward from the impact point.

The droplet shape appeared almost axisymmetric at $T_{w}=500{ }^{\circ} \mathrm{C}$, while asymmetric shapes were observed at lower temperatures. The reason for this is discussed as follows. When the droplet impacts obliquely on the solid at $T_{w}=170{ }^{\circ} \mathrm{C}$, the droplet is in direct contact with the solid. Most of the liquid moves along the tilted surface due to impact inertia, and the velocity of the liquid decreases in the vicinity of solid surface owing to viscous wall friction. As a consequence, the droplet was elongated in the $x$ direction. For $T_{w}=200{ }^{\circ} \mathrm{C}$, a similar deformation occurred. In addition to this, the blowout of boiling vapor bubbles promoted the disintegration of the droplets. The shape of the droplets was essentially asymmetric. For $T_{w}=300{ }^{\circ} \mathrm{C}$, blowout of vapor bubbles due to boiling was observed, although the probability of direct liquid/solid contact was smaller than that for lower temperatures. Thus, the droplet shape was asymmetric as well. For $T_{w}=500{ }^{\circ} \mathrm{C}$, the droplet was insulated from the solid by the vapor film soon after the impact. There was little viscous wall friction acting on the droplet, and little blowout of vapor bubbles occurred. The droplet shape could be kept almost axisymmetric.

In the present experiments, numerous instantaneous images of droplets were taken under the same experimental conditions assuming the repeatability of droplet motion. The photographic method was validated from the properties of the droplet images. For the cases of $T_{w}=170$ and $500{ }^{\circ} \mathrm{C}$, the droplet shapes showed good repeatability during the entire deformation process, although some scatter of the shape was seen later. For $T_{w}=200$ and $300{ }^{\circ} \mathrm{C}$, the repeatability of the droplet shapes was good in the beginning, and then later became poor because of the blowout of vapor bubbles. As a whole, it was concluded that moderate repeatability of droplet shapes was obtained.

\section{B. Collision behavior of droplets on the solid at $500{ }^{\circ} \mathrm{C}$}

In Fig.9, the droplet shape appears almost axisymmetric at $T_{w}=500{ }^{\circ} \mathrm{C}$. An additional experiment was conducted to confirm whether or not this tendency is seen at a higher tilt angle. Figure 10 shows the experimental results for $d_{p}=0.61 \pm 0.01 \mathrm{~mm}, v=2.6 \pm 0.05 \mathrm{~m} / \mathrm{s}, \alpha=45^{\circ}\left(W e_{n}=28\right)$, and $T_{w}=$ $500 \pm 10^{\circ} \mathrm{C}$. After the collision, the droplet spreads radially, constricts, and then is elongated upward in the shape of a bowling pin; then, it rebounds off the heated surface. The shape appears almost axisymmetric in the whole collision process. 
The axisymmetric motion of droplets in oblique collisions at a high solid temperature has also appeared in previous reports $[11,12,15,19]$ in which the collision behaviors of droplets were investigated using only one camera. In a strict sense, the axisymmetric shape of droplets cannot be reviewed by single-camera photography. Since the two-directional photography technique was used in the present study, the quantitative measurement of spreading diameters of droplets in two directions was conducted. Figure 11 shows the time evolution of spreading diameters $\left(d_{x}\right.$ and $\left.d_{y}\right)$ of the droplet under the same experimental conditions as those shown in Fig. 10. The definitions of $d_{x}$ and $d_{y}$ were given in the figure. The $y$ axis is taken in the horizontal direction and $d_{y}$ is the spreading diameter in the $y$-direction. The spreading diameter, $d_{x}$, is measured from the side-view images of droplets, and $d_{y}$ is evaluated from droplets images taken from a bird's-eye view. It is noted that $d_{x}$ and $d_{y}$ are equal to the pre-impact diameter $d_{p}$ at early times. In addition, it is difficult to accurately measure $d_{y}$ when the droplets are elongated in the shape of a bowling pin. The images of droplet are not clear at later times due to the restrictions of the lens system. For these reasons, $\tau_{n}$ ranges from 0 to 2.7 in the figure. The diameters $d_{x}$ and $d_{y}$ increased with time, reached maximum extensions, and then decreased. On the whole, the time histories of the two diameters are in good agreement with each other. The axisymmetric motion of droplets was confirmed quantitatively.

The Weber number has been regarded as a key parameter for the collision of droplets with a hot solid. In a strict sense, droplet collision phenomena cannot be correlated by the Weber number alone because of the presence of other parameters affecting the motion of droplets. In our previous work [6], the normal collision of a water droplet with a hot solid was investigated. It was found that the motion of a large droplet with $d_{p}=2.5 \mathrm{~mm}$ showed similar trends to that of a small one with $d_{p}=0.6$ $\mathrm{mm}$ for the same Weber number, when $T_{w}=500{ }^{\circ} \mathrm{C}$. In the present study, a similar experiment was conducted to determine whether the dynamical similarity of the oblique collision behavior of a droplet holds true for droplets with $d_{p}=2.5 \mathrm{~mm}$ and $d_{p}=0.6 \mathrm{~mm}$ under the same $W e_{n}$. Figure 12 shows the time evolution of a droplet impinging on the Inconel alloy for $d_{p}=2.49 \pm 0.08 \mathrm{~mm}, v=$ $0.90 \pm 0.02 \mathrm{~m} / \mathrm{s}, \alpha=30^{\circ}\left(W e_{n}=20\right)$, and $T_{w}=500{ }^{\circ} \mathrm{C}$. $W e_{n}$ and $T_{w}$ are the same as those for the conditions in Fig. 9. In addition to the elapsed time $\left(t_{e}\right)$, dimensionless times $\left(\tau_{n}\right)$ were drawn. After the collision, the droplet spreads radially, reaches its maximum extension (at $t_{e}=3.15-4.16 \mathrm{~ms}$ ), and then constricts. After $t_{e}=7.02 \mathrm{~ms}$, the liquid is elongated upward in the shape of a bowling pin; then it rebounds off the surface. In (b), a vapor film was observed at the liquid/solid interface as in Fig. 9(b). The droplet shape appears almost axisymmetric during the collision. The shape of the droplet at any dimensionless time $\left(\tau_{n}\right)$ in Fig. 12 is very similar to that in Fig. 9.

The time evolutions of the apparent contact length of large and small droplets were measured, and a quantitative comparison was conducted. Figure 13 demonstrates the apparent dimensionless contact lengths for large and small droplets for $W e_{n}=20$ and $T_{w}=500{ }^{\circ} \mathrm{C}$. The contact length, $l$, is defined in Fig.4. The contact lengths were zero at the moment of droplet impact; it increased with time, reached a maximum extension, and then decreased. Although a slight difference was observed at later times, the two results are in good agreement. The actual timescale for the motion of a large 
droplet was approximately nine times that of a small droplet, but a moderate dynamical similarity of droplet motion based on $W_{n}$ alone was obtained.

We conducted another quantitative comparison. Figure 14 shows the time evolutions of the positions of leading and trailing edges for large and small droplets for $W e_{n}=20$ and $T_{w}=500{ }^{\circ} \mathrm{C}$ (see also Fig. 4). The black and white symbols present data for large and small droplets, respectively. The triangles give the arithmetic mean values of the leading and trailing positions of the droplet. The solid line presents the dimensionless component of the impact velocity tangential to the solid surface as

$$
\frac{x}{d_{p}}=\tau \sin \alpha
$$

The leading edge of the large and small droplets moved monotonically downward along the solid surface with time. In contrast, the trailing edge of the droplet advanced upward early on the graph and then began to move downward. The arithmetic mean value of the two distances changes almost linearly with time and agrees with Eq. (7). Therefore, we concluded that the slip velocity of the droplet in the $x$ direction is almost the same as the tangential component of the impact velocity. These results also suggest that the momentum loss mainly due to viscous shear stress in the $x$ direction is very small. The results for small and large droplets are in good agreement with each other in the early stages; slight differences arise between them subsequently. A moderate dynamical similarity of droplet motion in the $x$ direction was also obtained.

Karl and Frohn [11] and Chen et al. [12] studied the deformation processes of droplets impacting obliquely onto a metal surface above the Leidenfrost temperatures. They proposed experimental correlations capable of predicting the maximum spreading length of a droplet in the $x$ direction based on the Weber number, $W e_{n}$, alone, as shown in Table 2. Incidentally, in cases of normal collisions, other researchers [8-10, 37] have proposed experimental formulae capable of predicting three parameters: (a) the maximum spreading diameters of a droplet, (b) the time required for the circular water film to reach the maximum spreading diameter, and (c) the resident time of droplets on a hot surface from the moment of impact to rebounding off the surface, as shown in Table 2. They are correlated with functions of the Weber numbers defined in Eq. (1). Since a moderate dynamical similarity of droplet motion based on $W e_{n}$ alone was obtained in the present study, the authors expected that the experimental correlations for normal collisions were applicable to the oblique collisions by using $W e_{n}$. In order to confirm this hypothesis, we conducted the experiments under the conditions that $T_{w}=500{ }^{\circ} \mathrm{C} ; d_{p}=0.6 \mathrm{~mm}$ or $2.5 \mathrm{~mm}$; and $\alpha=0^{\circ}, 20^{\circ}, 30^{\circ}$, and $45^{\circ}$.

Figure 15 demonstrates the relationship between the dimensionless maximum spreading diameter $d_{\max } / d_{p}$ and $W e_{n}$. The maximum spreading diameters were obtained from the side-view images. Several experimental formulae, as listed in Table 2, are also drawn in the figure. The solid line presents the experimental formula proposed by Hatta et al. [10] as 


$$
\frac{d_{\max }}{d_{p}}=0.093 W e_{n}^{0.074}+1 \text {, }
$$

where $W e$ was replaced with $W e_{n}$ in the original correlation. Further, $d_{\max }$ presents the maximum spreading length in the $x$ direction. A similar modification was employed to correlations proposed by Akao et al. [9], Ueda et al. [8] and Araki and Moriyama [37]. It is clear that $d_{\max } / d_{p}$ increases with increasing $W e_{n}$ which is associated with the impact inertia of droplets normal to the solid surface. The experimental results agree moderately well with the correlations. In addition, all correlations show similar trends to each other in the range of $\mathrm{We}_{\mathrm{n}}>10$, although some difference is observed. Any correlation drawn in the figure is applicable to the rough prediction of the maximum spreading diameter of droplet.

Figure 16 shows the relationship between the dimensionless time, $\tau_{\max }$, required for the circular water film to reach the maximum spreading diameter and $W e_{n .}$. The lines in the figure present the modified experimental formulae obtained by other researchers as listed in Table 2. Here, the Weber numbers are replaced by $W e_{n}$, and the time is normalized by Eq. (4). The dimensionless time, $\tau_{\max }$, increases with increasing $W e_{n}$. The experimental results show similar trends to the modified correlations.

Figure 17 presents the relation between the dimensionless resident time, $\tau_{r}$, of droplets and $W e_{n}$. Appreciable deviation is seen between the correlation of Chen et al. [12] and the present results. However, other modified correlations in Table 2 agree reasonably well with the present results. It was found from Figs. 15-17 that experimental correlations for normal collisions are roughly applicable to the oblique collisions by using $W e_{n}$.

The error range of each measured resident time, $\tau_{r}$, in Fig. 17 is fairly large compared to that of $\tau_{\max }$ in Fig. 16, because the repeatability of droplet shape became worse at later times, as previously mentioned. Furthermore, the measured resident time, $\tau_{r}$, scatters as compared to $\tau_{\max }$. In Fig. 13 , $\tau_{\max }$ for small and large droplets are very similar, although the larger diameter droplets rebound off the solid at an earlier time. These facts suggest that the resident time, $\tau_{r}$, was influenced not only by $W e_{n}$, but also by other factors.

Richard and Quéré [38] showed that water drops can rebound off highly hydrophobic surfaces even at room temperature. Therefore, many possible factors affect the resident time, including the temperature at the liquid/solid interface, the Weber number, the Reynolds number, wettability between the liquid and the solid, surface roughness, and so on. In the present case, it is considered that the droplet was isolated from the solid by the vapor layer. Further, the temperature of the solid, the material of the test piece, and the type of liquid were unchanged. The differences in $\tau_{r}$ arose probably from the Reynolds number associated with internal viscous shear stress. 


\section{CONCLUSIONS}

The oblique collisions of water droplets with a hot solid were studied by means of two-directional flash photography. The results are summarized as follows.

(1) The effect of varying the temperature of a solid was investigated using small droplets for $W e_{n}=$ 20-30. At a surface temperature less than or equal to $400{ }^{\circ} \mathrm{C}$, the shape of the droplet was apparently asymmetrical during the collision. The boiling vapor bubbles gave rise to the formation of secondary droplets when the temperature was $200{ }^{\circ} \mathrm{C}, 300{ }^{\circ} \mathrm{C}$, and $400{ }^{\circ} \mathrm{C}$. At $500{ }^{\circ} \mathrm{C}$, droplet rebounding phenomena were observed. The droplet shape remained almost axisymmetric even at $\alpha=45^{\circ}$.

(2) For the same $W e_{n}$, a moderate dynamical similarity of droplet motion was observed when the temperature was $500{ }^{\circ} \mathrm{C}$.

(3) At $500{ }^{\circ} \mathrm{C}$, we observed an increase in (a) the spreading length of droplets, (b) the time required for the circular water film to reach the maximum spreading diameter, and (c) the droplet resident time on a hot surface with increasing Weber numbers. The Weber number based on the normal velocity component is a suitable parameter for evaluating deformation processes of droplets in both oblique and normal collisions.

\section{ACKNOWLEDGMENTS}

The present study was supported by a Grant-in-Aid for Scientific Research (\#21560212 ) from the Japan Society for Promotion of Science.

\section{NOMENCLATURE}

$C_{P} \quad$ specific heats, $\mathrm{J} /(\mathrm{kg} \mathrm{K})$

$d_{\max } \quad$ maximum spreading diameter of droplet in normal collision, $\mathrm{m}$

$d_{p} \quad$ pre-impact diameter of droplet, $\mathrm{m}$

$d_{x} \quad$ spreading diameter measured from side view images, $\mathrm{m}$

$d_{y} \quad$ horizontal spreading diameter measured from bird's-eye view images, $\mathrm{m}$

l apparent contact length, $\mathrm{m}$

$T_{C}, T_{H}$ temperatures of materials $\mathrm{C}$ and $\mathrm{H},{ }^{\circ} \mathrm{C}$

$T_{i} \quad$ interfacial temperature, ${ }^{\circ} \mathrm{C}$

$T_{w} \quad$ temperature of the solid, ${ }^{\circ} \mathrm{C}$

$t_{e} \quad$ time, $\mathrm{s}$

$t_{\max } \quad$ time required for the circular water film to reach the maximum spreading diameter

$t_{r} \quad$ droplet resident time on a hot surface

$v \quad$ impact velocity of droplet, $\mathrm{m} / \mathrm{s}$

$x \quad$ coordinate along the tilted surface, $\mathrm{m}$

$x_{1}, x_{2} \quad$ leading and trailing edges of droplet along the tilted surface, $\mathrm{m}$ 
$\begin{array}{ll}\text { We } & \text { Weber number } \\ W e_{n} & \text { Weber number based on the normal velocity component }\end{array}$

Greek symbols

$\alpha \quad$ tilt angle, degrees

$\Delta L \quad$ small distance moved by a droplet, $\mathrm{m}$

$\Delta L_{w} \quad$ spacing between the bottom of pre-impact droplet and solid, $\mathrm{m}$

$\Delta t \quad$ time interval, $\mathrm{s}$

$\rho \quad$ liquid density, $\mathrm{kg} / \mathrm{m}^{3}$

$\sigma \quad$ surface tension, $\mathrm{N} / \mathrm{m}$

$\lambda \quad$ thermal conductivity, $\mathrm{W} /(\mathrm{mK})$

$\tau \quad$ dimensionless time

$\tau_{\max } \quad$ dimensionless time required for the circular water film to reach the maximum spreading diameter

$\tau_{n} \quad$ dimensionless time based on the normal velocity component

$\tau_{r} \quad$ dimensionless droplet resident time on a hot surface

\section{REFERENCES}

[1] Rein, M., 1993, "Phenomena of Liquid Drop Impact on Solid and Liquid Surfaces”, Fluid Dynamics Research, 12, pp. 61-93.

[2] Rein, M., 2002, “Interactions Between Drops and Hot Surfaces”, In Drop-Surface Interactions, CISM Courses and Lectures no. 456, Springer-Verlag Wien, New York, pp. 185-217.

[3] Yarin, A. L., 2006, “Drop Impact Dynamics: Splashing, Spreading, Receding, Bouncing...”, Annual Review of Fluid Mechanics, 38, pp. 159-192.

[4] Skripov, V. P., 1974, "Metastable Liquids”, John Wiley and Sons, New York, pp. 83-177.

[5] Avedisian, C. T., 1985, “The Homogenous Nucleation Limits of Liquids”, Journal of Physical and Chemical Reference Data, 14, pp. 695-729.

[6] Fujimoto, H., Oku, Y., Ogihara, T., and Takuda, H., 2010, "Hydrodynamics and Boiling Phenomena of Water Droplets Impinging on Hot Solid”, International Journal of Multiphase Flow, 36, pp. 620-642.

[7] Wachters, L. H. J. and Westerling, N. A. J., 1966, “The Heat Transfer from a Hot Wall to Impinging Water Drops in the Spheroidal State”, Chemical Engineering Science, 21, pp. 1047-1056.

[8] Ueda, T., Enomoto, T., and Kanetsuki, M., 1979, "Heat Transfer Characteristics and Dynamic Behavior of Saturated Droplets Impinging on a Heated Vertical Surface”, Bulletin of JSME, 22, pp. 724-732. 
[9] Akao, F., Araki, K., Mori, S., and Moriyama, A., 1980, "Deformation Behaviors of a Liquid Droplet Impinging onto Hot Metal Surface”, Transactions of the Iron and Steel Institute of Japan, 20, pp. 737-743.

[10] Hatta, N., Fujimoto, H., Kinoshita, K., and Takuda, H., 1997, "Experimental Study of Deformation Mechanism of a Water Droplet Impinging on Hot Metallic Surfaces above the Leidenfrost Temperature”, Transactions of The ASME Journal of Fluid Engineering, 119, pp. 692-699.

[11] Karl, A. and Frohn, A., 2000, "Experimental Investigation of Interaction Processes Between Droplets and Hot Walls”, Physics Of Fluids, 12, pp. 785-796.

[12] Chen, R., Chiu, S., and Lin, T., 2007, “On the Collision Behaviors of a Diesel Drop Impinging on a Hot Surface”, Experimental Thermal and Fluid Science, 32, pp. 587-595.

[13] Kang, B. S. and Lee, D. H., 2000, “On the Dynamic Behavior of a Liquid Droplet Impacting upon an Inclined Heated Surface”, Experiments in Fluids, 29, pp. 380-387.

[14] Šikalo, Š., Tropea, C., and Ganić, E. N., 2005, "Impact of Droplets onto Inclined Surfaces", Journal of Colloid and Interface Science, 286, pp. 661-669.

[15] Ko and Chung, 1996, “An Experiment on the Breakup of Impinging Droplets on a Hot Surface”, Experiments in Fluids, 21, pp. 118-123.

[16] Moreira, A. L. N., Moita, A. S., Cossali, E., Marengo, M., and Santini, M., 2007, "Secondary Atomization of Water and Isooctane Drops Impinging on Tilted Heated Surfaces”, Experiments in Fluids, 43, pp. 297-313.

[17] Castanet, G., Lienart, T., and Lemoine, F., 2009, "Dynamics and Temperature of Droplets Impacting onto a Heated Wall,” International Journal of Heat and Mass Transfer, 52, pp. 670-679.

[18] Kang, C. W. and Ng, H. W., 2006, "Splat Morphology and Spreading Behavior Due to Oblique Impact of Droplets onto Substrates in Plasma Spray Coating Process”, Surface \& Coatings Technology, 200, pp. 5462-5477.

[19] Anders, K., Roth, N., and Frohn, A., 1993, “The Velocity Change of Ethanol Droplets during Collision with a Wall Analysed by Image Processing”, Experiments in Fluids, 15, pp. 91-96.

[20] Seki, M., Kawamura, H., and Sanokawa, K., 1978, “Transient temperature profile of a hot wall due to an impinging liquid jet”, ASME Journal of Heat Transfer, 100, pp. 167-169.

[21] Aziz, S. D., and Chandra, S., 2000, “Impact, recoil and splashing of molten metal droplets”, International Journal of Heat and Mass Transfer, 43, pp. 2841-2857.

[22] Bernardin, J. D. and Mudawar, I., 1999, "The Leidenfrost point: Experimental study and assessment of existing models”, ASME Journal of Heat Transfer, 121, pp. 894-903.

[23] Bernardin, J. D., and Mudawar, I., 2002, “A cavity activation and bubble growth model of the Leidenfrost point”, ASME Journal of Heat Transfer, 124, pp. 864-874.

[24] Bernardin, J. D. and Mudawar, I., 2004, “A Leidenfrost point model for impinging droplets and sprays”, ASME Journal of Heat Transfer, 126, pp. 272-278. 
[25] Cossali, G. E., Marengo, M., and Santini, M., 2008, "Thermally induced secondary drop atomisation by single drop impact onto heated surfaces”, International Journal of Heat and Fluid Flow, 29, pp. 167-177.

[26] Furuya, M., and Arai, T., 2008, “Effect of surface property of molten metal pools ontriggering of vapor explosions in water droplet impingement”, International Journal of Heat and Mass Transfer, 51, pp. 4439-4446.

[27] Carslaw, H. S., and Jaeger, J. C., 1959, “Conduction of Heat in Solids”, Second edition, Oxford University Press, Oxford, pp. 88.

[28] Eckert, E. R. G., and Drake Jr., R. M., 1972, “Analysis of Heat and Mass Transfer”, McGraw-Hill, New York, pp. 158-166.

[29] Lienhard, J. H., 1976, “Correlation for the limiting liquid superheat”, Chemical Engineering Science, 31, pp. 847-849.

[30] Derewnicki, K. P., 1985, "Experimental studies of heat transfer and vapour formation in fast transient boiling”, International Journal of Heat and Mass Transfer, 28, pp. 2085-2092.

[31] Iida, Y., and Okuyama, K., and Sakurai, K., 1994, "Boiling nucleation on a very small film heater subjected to extremely rapid heating”, International Journal of Heat and Mass Transfer, 37, pp. 2771-2780.

[32] Avedisian, C. T., Osborne, W. S., Mcleod, F. D., and Curley, C. M., 1999, "Measuring bubble nucleation temperature on the surface of a rapidly heated thermal ink-jet heater immersed in a pool of water”, Proceedings of the Royal Society of London, A 455, pp. 3875-3899.

[33] Glod, S., Poulikakos, D., Zhao, Z., and Yadigaroglu, G., 2002, “An investigation of microscale explosive vaporization of water on an ultrathin Pt wire”, International Journal of Heat and Mass Transfer, 45, pp. 367-379.

[34] Thomas, O. C., Cavicchi, R. E., and Tarlov, M. J., 2003, "Effect of surface wettability on fast transient microboiling behavior”, Langmuir, 19, pp. 6168-6177.

[35] Hong, Y., Ashgriz, N., and Andrews, J., 2004, "Experimental study of bubble dynamics on a micro heater induced by pulse heating”, ASME Journal of Heat Transfer, 126, pp. 259-271.

[36] Fujimoto, H., Shiraishi, H. and Hatta, N., 2000, "Evolution of Liquid/Solid Contact Area of a Drop Impinging on a Solid Surface”, International Journal of Heat and Mass Transfer, 43, pp. 1673-1677.

[37] Araki, K. and Moriyama, A., 1981, “Theory on Deformation Behavior of a Liquid Droplet Impinging onto Hot Metal Surface”, Transactions of the Iron and Steel Institute of Japan, 21, pp. 583-590.

[38] Richard, D and Quéré, D, 2000, “Bouncing water drops”, Europhysics Letters, 50, pp.769-775. 
Table and Figure Captions:

Table 1 List of experimental conditions

Table 2 Formulas proposed in previous studies

Fig. 1 Schematic of experimental apparatus

Fig. 2 Schematic of photography setup

Fig. 3 Examples of the double-exposed images of the droplet

Fig. 4 Definition of coordinate and apparent contact length, $l$, of a droplet

Fig. 5 Deformation behavior of water droplets impacting on Inconel surface at $T_{w}=170 \pm 10{ }^{\circ} \mathrm{C}$ and $\alpha=30^{\circ}$ for $d_{p}=0.61 \pm 0.01 \mathrm{~mm}$ and $v=2.1 \pm 0.05 \mathrm{~m} / \mathrm{s}$. (a) Double-exposure backlit images of droplet taken by Camera A shown in Fig. 2; (b) bird's-eye view images of droplets taken by Camera B

Fig. 6 Deformation behavior of water droplets impacting on Inconel surface at $T_{w}=200 \pm 10{ }^{\circ} \mathrm{C}$ and $\alpha=30^{\circ}$ for $d_{p}=0.59 \pm 0.01 \mathrm{~mm}$ and $v=2.1 \pm 0.05 \mathrm{~m} / \mathrm{s}$

Fig. 7 Deformation behavior of water droplets impacting on Inconel surface at $T_{w}=300 \pm 10{ }^{\circ} \mathrm{C}$ and $\alpha=30^{\circ}$ for $d_{p}=0.60 \pm 0.01 \mathrm{~mm}$ and $v=2.0 \pm 0.05 \mathrm{~m} / \mathrm{s}$

Fig. 8 Deformation behavior of water droplets impacting on Inconel surface at $T_{w}=400 \pm 10{ }^{\circ} \mathrm{C}$ and $\alpha=30^{\circ}$ for $d_{p}=0.60 \pm 0.01 \mathrm{~mm}$ and $v=2.1 \pm 0.05 \mathrm{~m} / \mathrm{s}$

Fig. 9 Deformation behavior of water droplets impacting on Inconel surface at $T_{w}=500 \pm 10{ }^{\circ} \mathrm{C}$ and $\alpha=30^{\circ}$ for $d_{p}=0.58 \pm 0.01 \mathrm{~mm}$ and $v=1.9 \pm 0.05 \mathrm{~m} / \mathrm{s}$

Fig. 10 Deformation behavior of water droplets impacting on Inconel surface at $T_{w}=500 \pm 10{ }^{\circ} \mathrm{C}$ and $\alpha=45^{\circ}$ for $d_{p}=0.61 \pm 0.01 \mathrm{~mm}$ and $v=2.6 \pm 0.05 \mathrm{~m} / \mathrm{s}$

Fig. 11 Time evolution of spreading diameters of droplet and their definitions

Fig. 12 Deformation behavior of water droplets impacting on Inconel surface at $T_{w}=500 \pm 10{ }^{\circ} \mathrm{C}$ and $\alpha=30^{\circ}$ for $d_{p}=2.49 \pm 0.08 \mathrm{~mm}$ and $v=0.90 \pm 0.02 \mathrm{~m} / \mathrm{s}$

Fig. 13 Time evolution of the contact length of large and small droplet. The impact conditions are the same as in Fig. 9 and Fig. 12. Note that the measurement uncertainty of $l / d_{p}$ is within \pm 0.04 for a small droplet and \pm 0.08 for a large droplet

Fig. 14 Time evolution of leading edges, trailing edges, and average values of large and small droplets. The impact conditions are the same as in Fig. 9 and Fig. 12. Note that the measurement uncertainty of $x / d_{p}$ is within \pm 0.04 for small droplets and \pm 0.08 for large droplets

Fig. 15 Relationship between dimensionless maximum spreading length of a droplet and Weber number based on normal velocity component

Fig. 16 Relationship between dimensionless time required for the circular water film to reach the maximum spreading diameter and Weber number based on normal velocity component

Fig. 17 Relationship between dimensionless droplet resident time on a hot surface and Weber number based on normal velocity component 
Table 1

\begin{tabular}{|c|c|c|c|c|c|}
\hline$T_{w},{ }^{\circ} \mathrm{C}$ & 170 & 200 & 300 & 400 & 500 \\
\hline$d_{p}, \mathrm{~mm}$ & 0.61 & 0.59 & 0.60 & 0.60 & $0.56-0.64,2.44-2.63$ \\
\hline$v, \mathrm{~m} / \mathrm{s}$ & 2.1 & 2.1 & 2.0 & 2.1 & $1.8-3.1,0.84-1.4$ \\
\hline$W e_{n}$ & 28 & 28 & 25 & 26 & $20-53$ \\
\hline$\alpha,{ }^{\circ}$ & 30 & 30 & 30 & 30 & $0-45$ \\
\hline$T_{i},{ }^{\circ} \mathrm{C}$ & 141 & 167 & 251 & 338 & 426 \\
\hline
\end{tabular}


Table 2

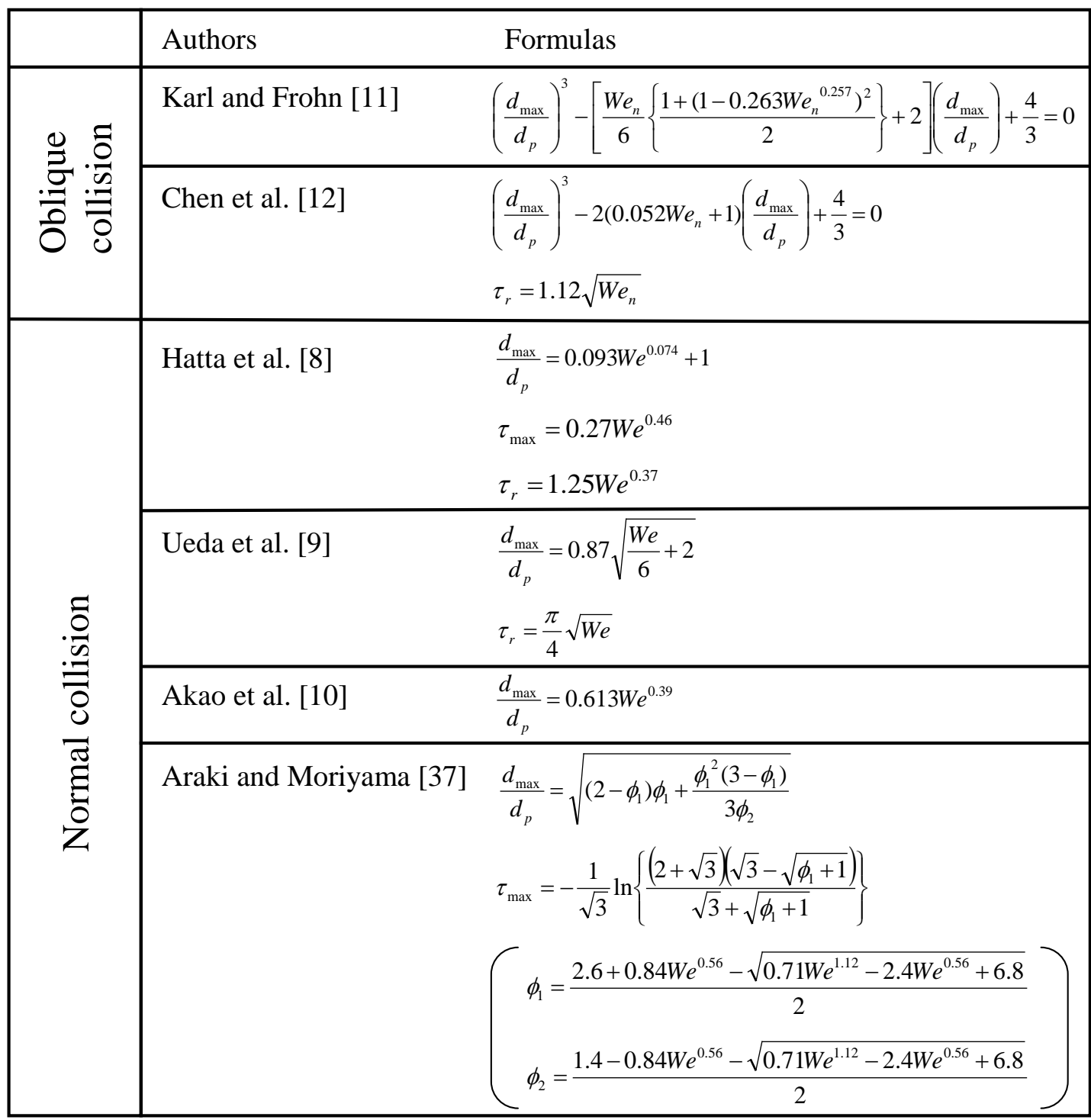




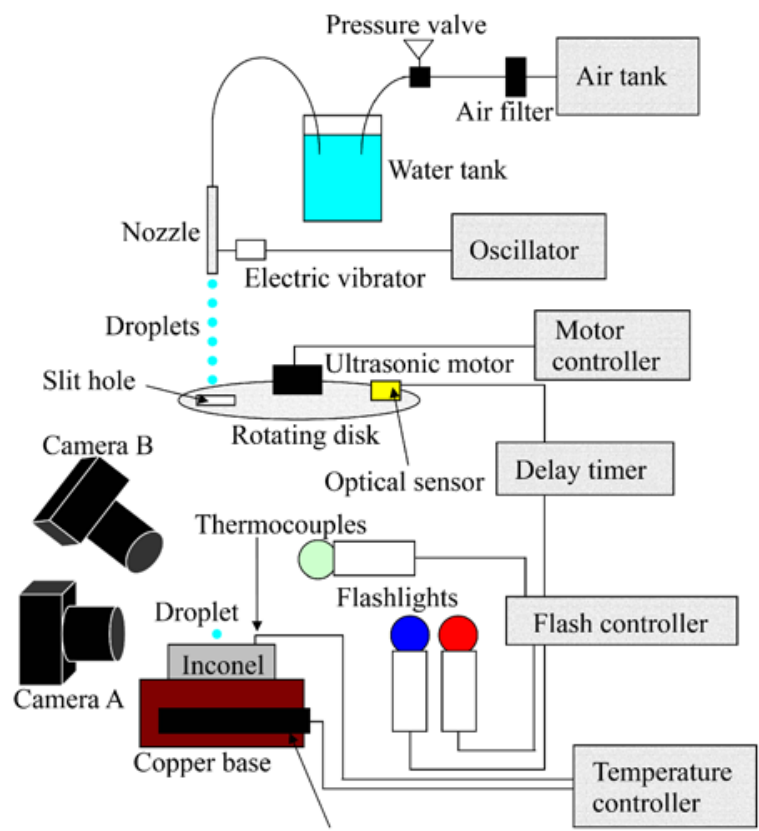

Electric heater

Fig1.tif 


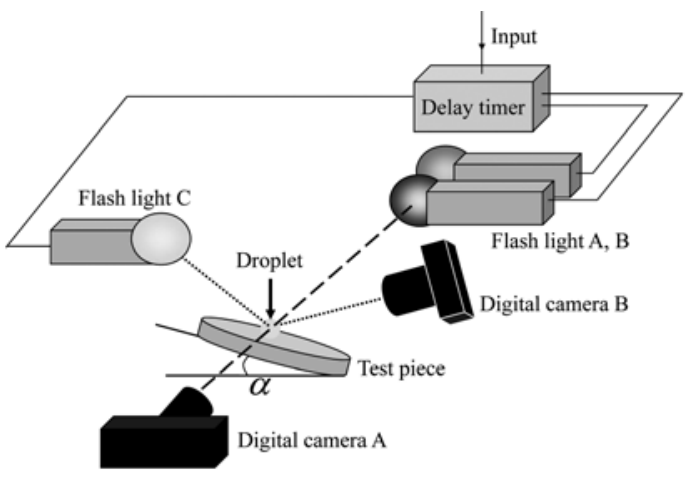

Fig2.tif 
(a)

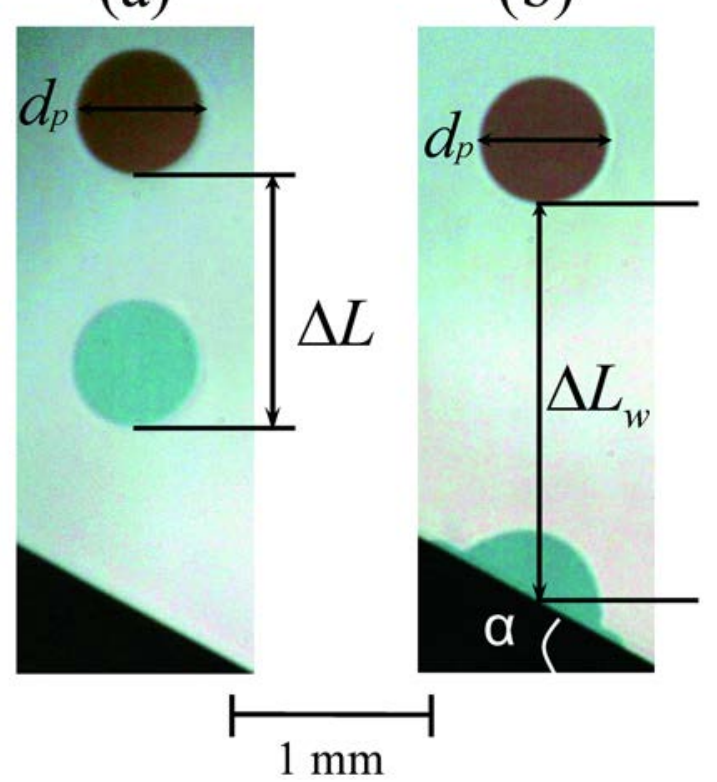

Fig3.tif 


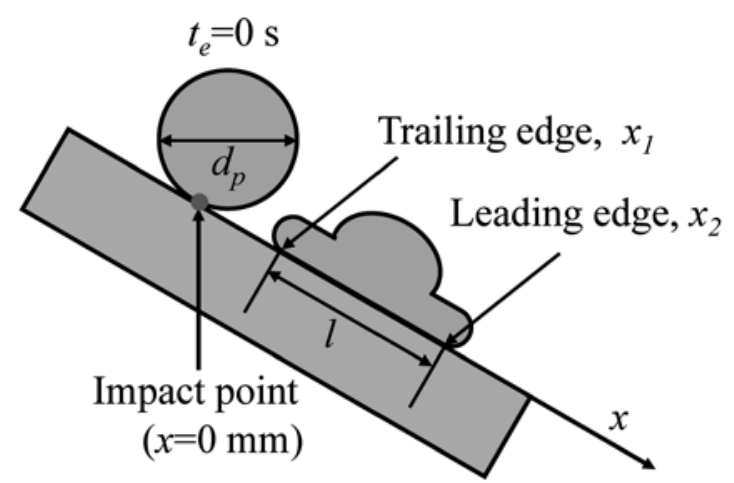

Fig4.tif 
(a)

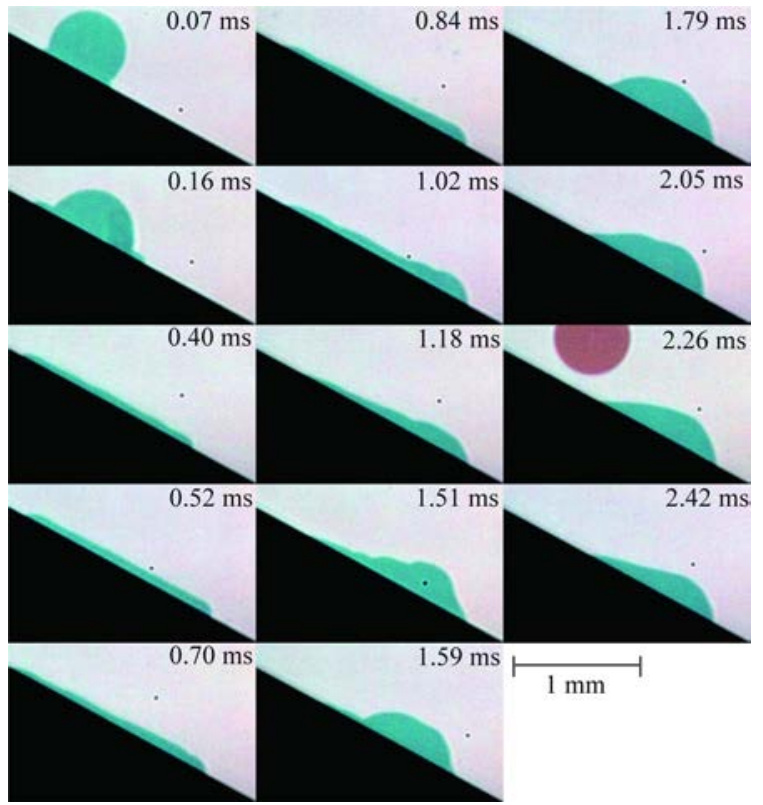

(b)

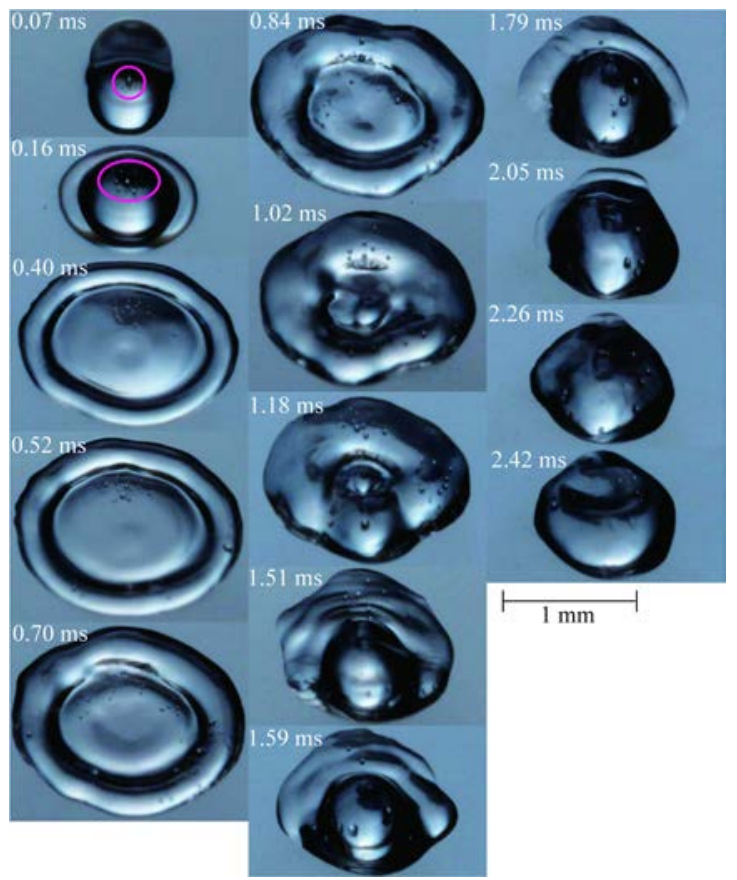

Fig5a.tif, fig5b.tif 
(a)

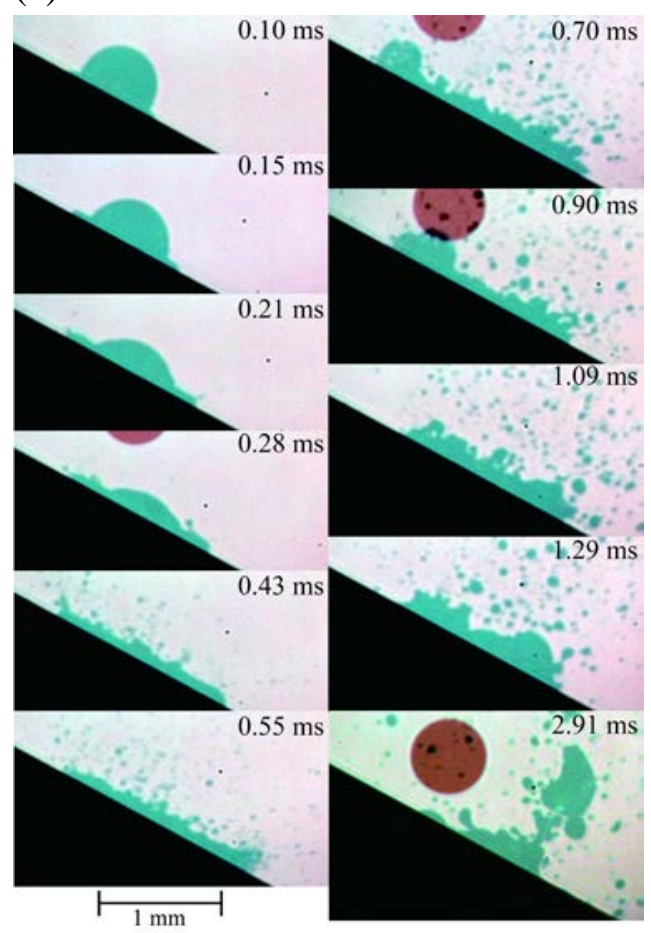

(b)

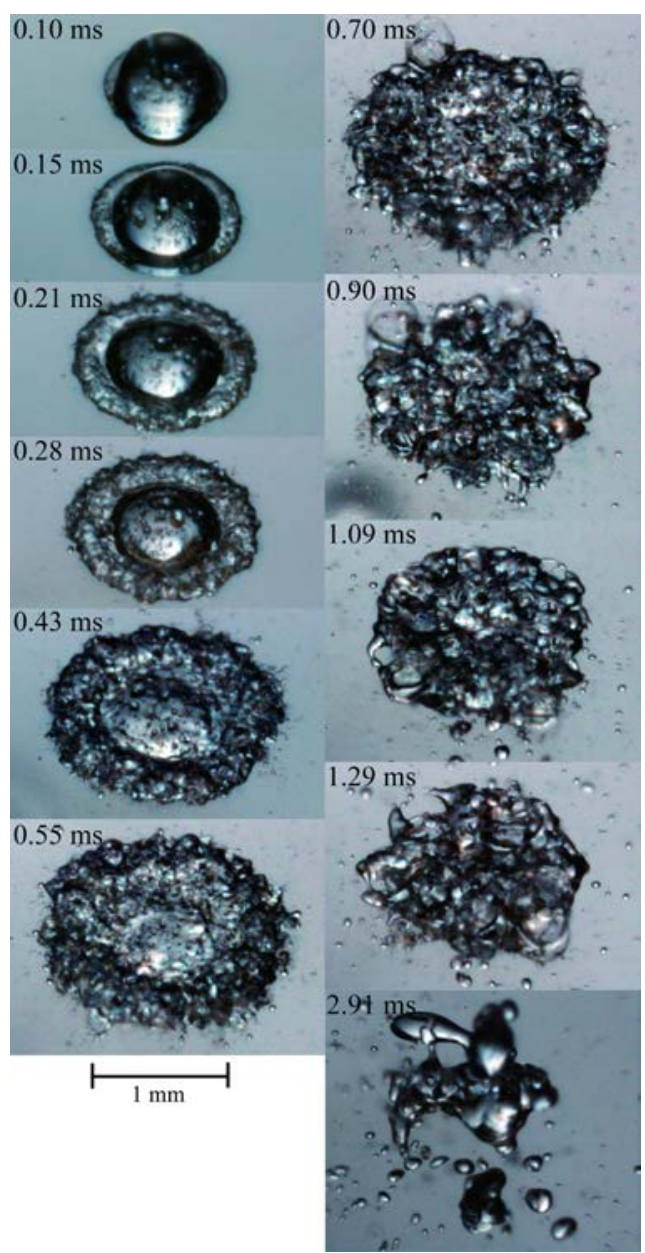

Fig6a.tif, fig6b.tif 
(a)

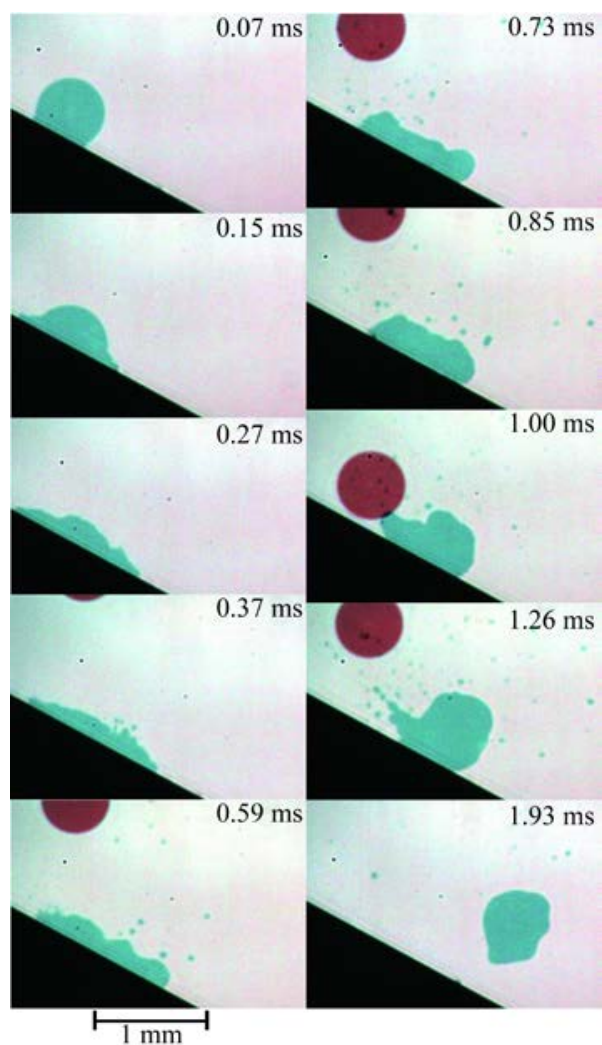

(b)

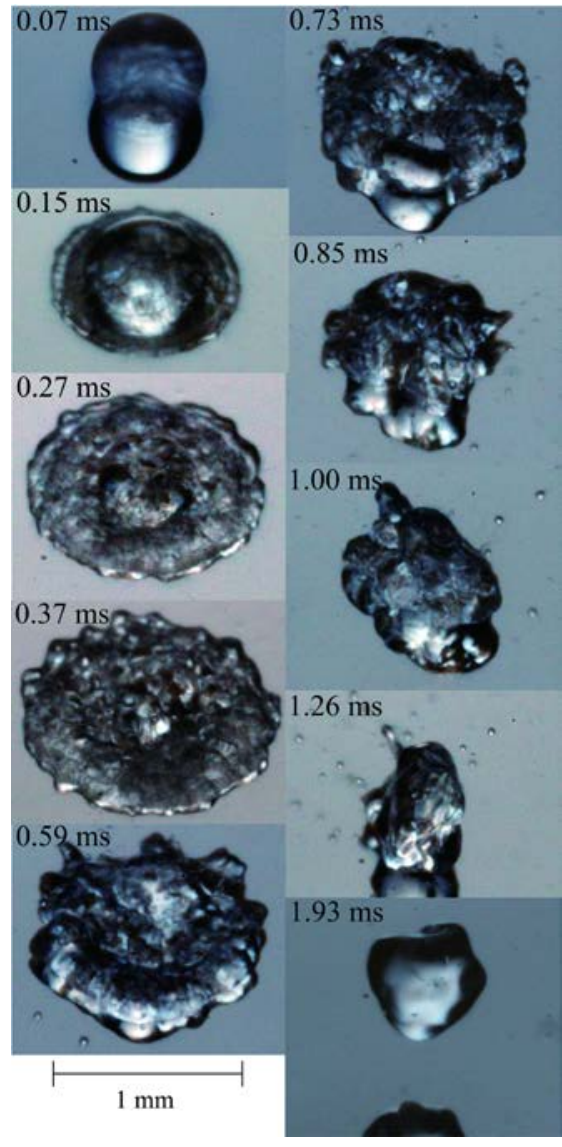

Fig7a.tif, fig7b.tif 
(a)

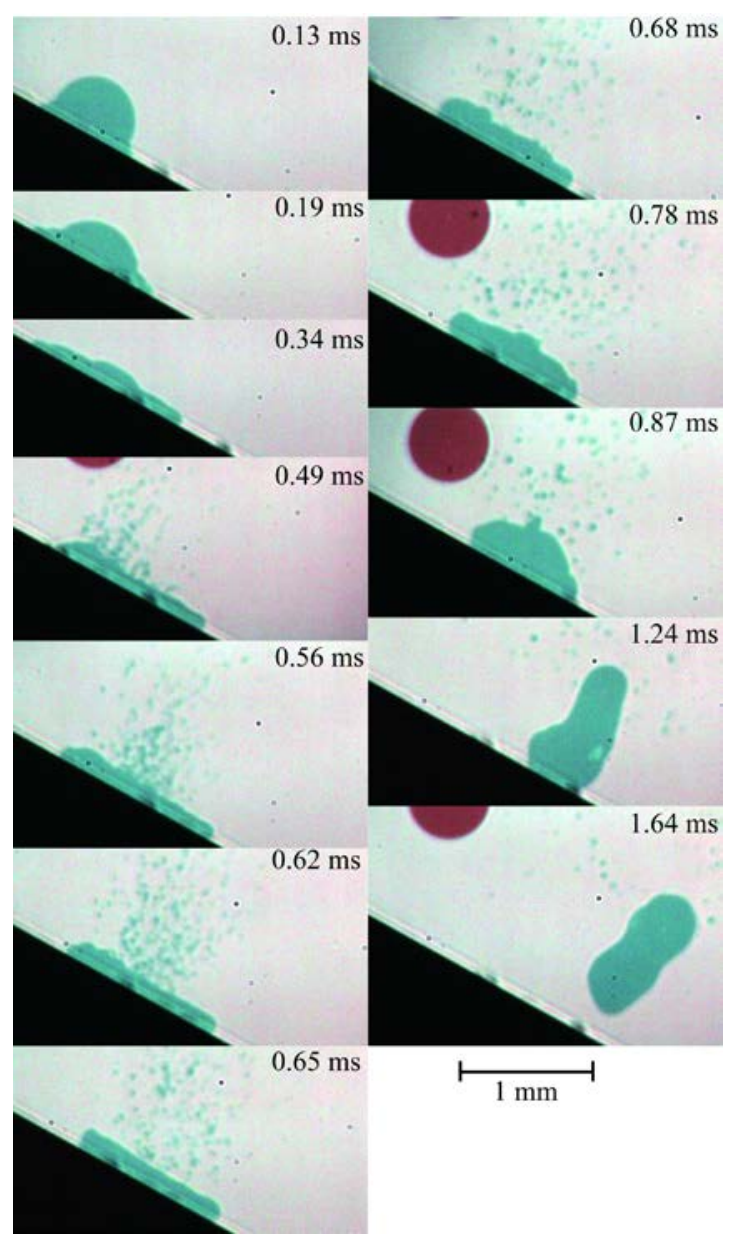

(b)

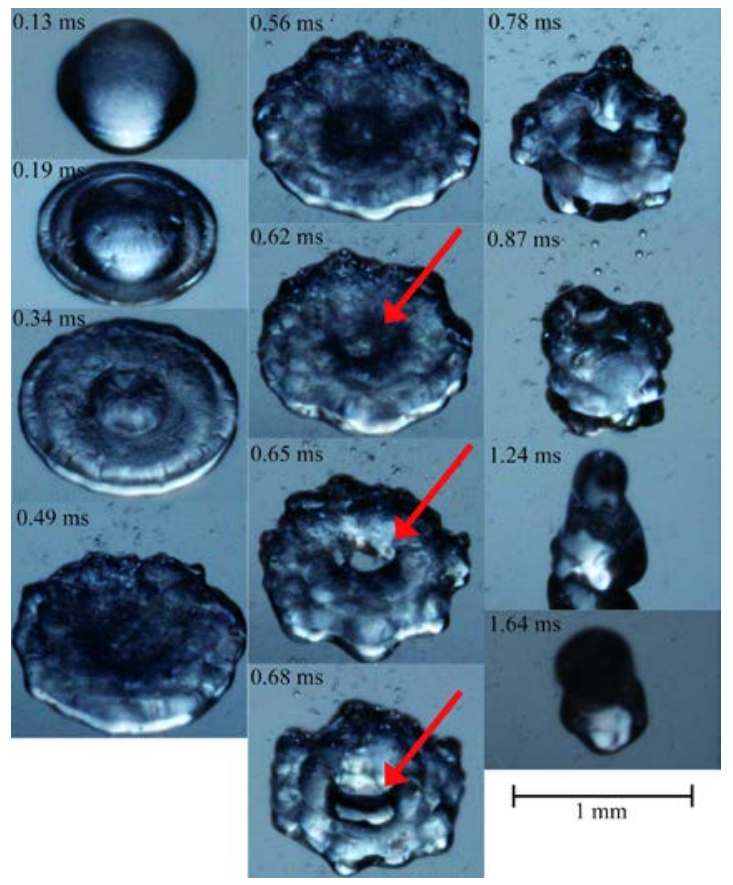

Fig8a.tif, fig8b.tif 
(a)

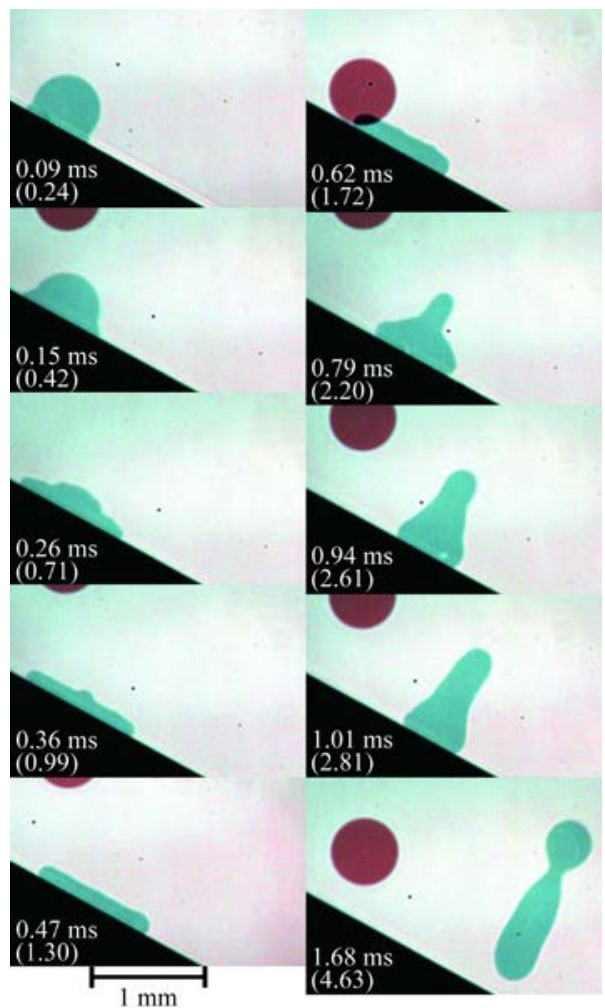

(b)

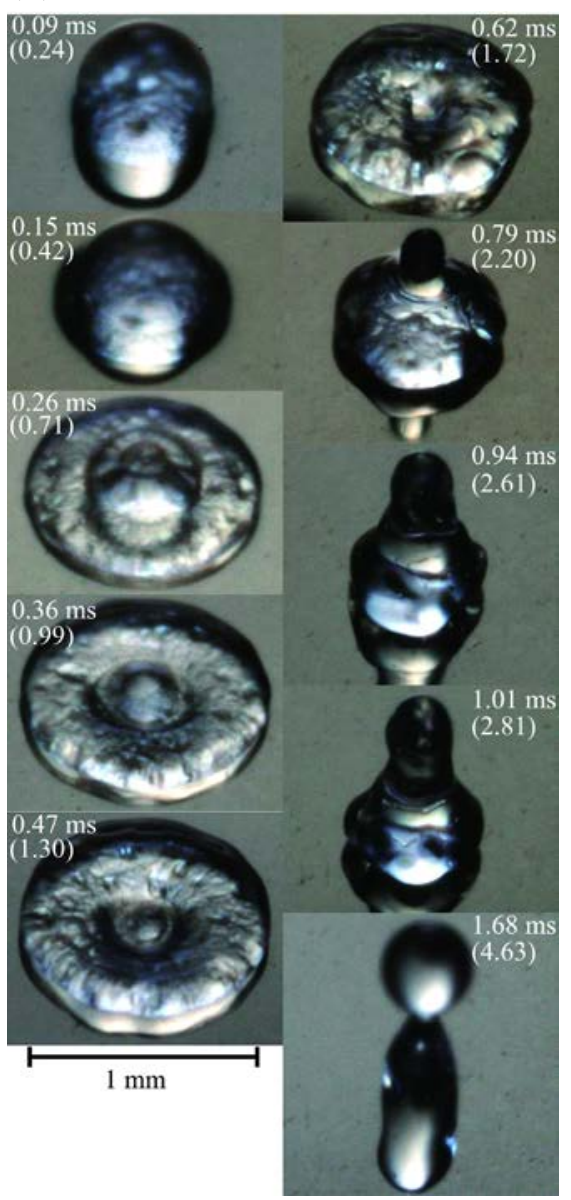

Fig9a.tif, fig9b.tif 
(a)

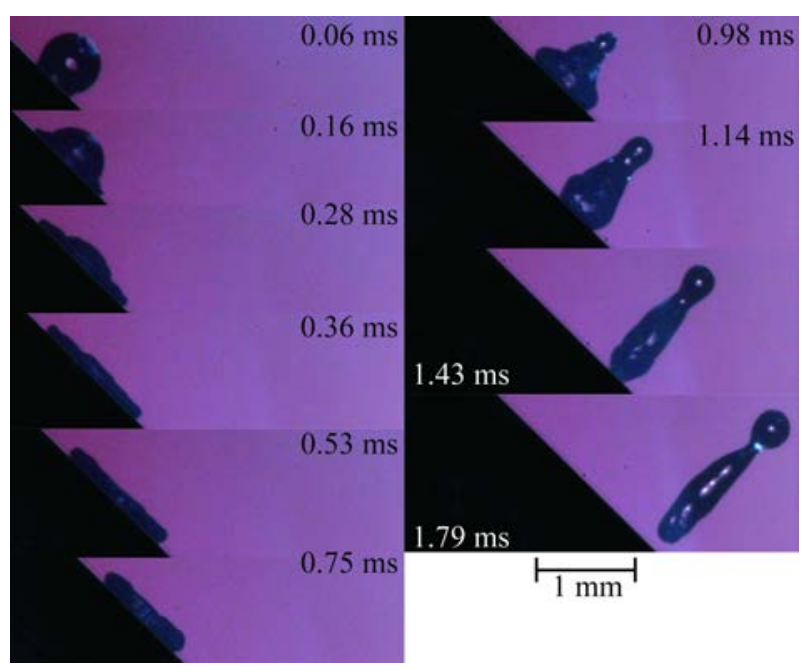

(b)

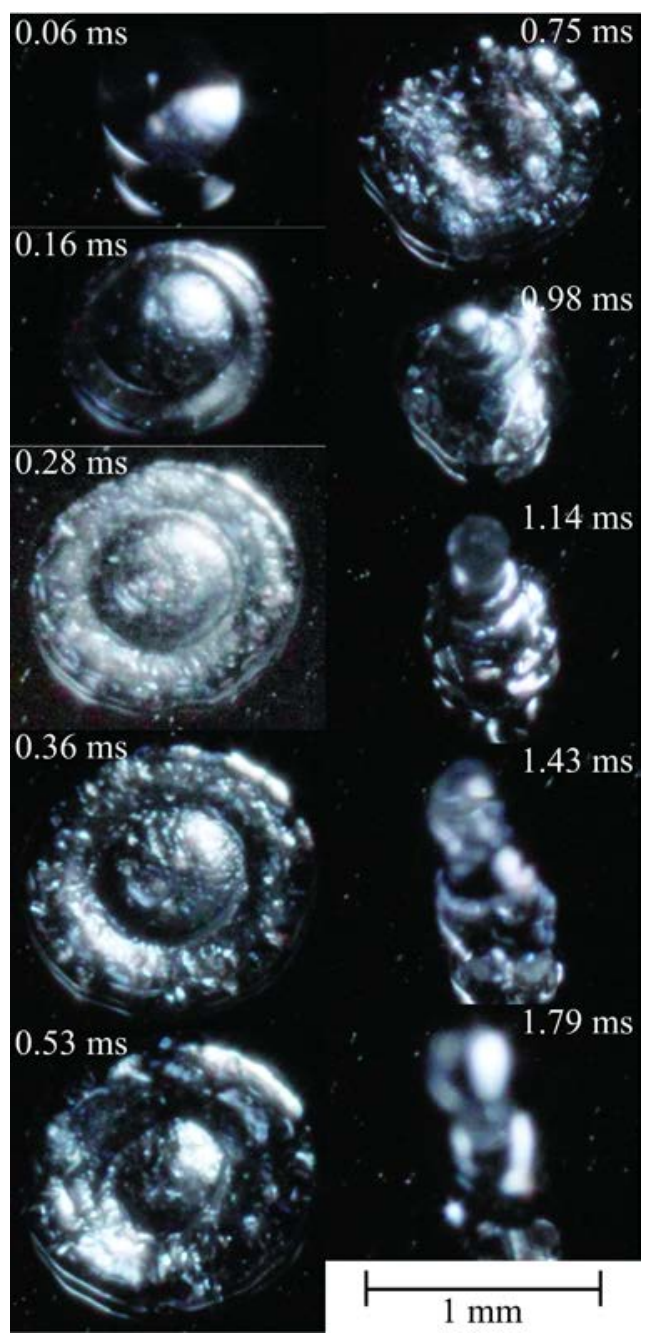

Fig10a.tif, fig10b.tif 


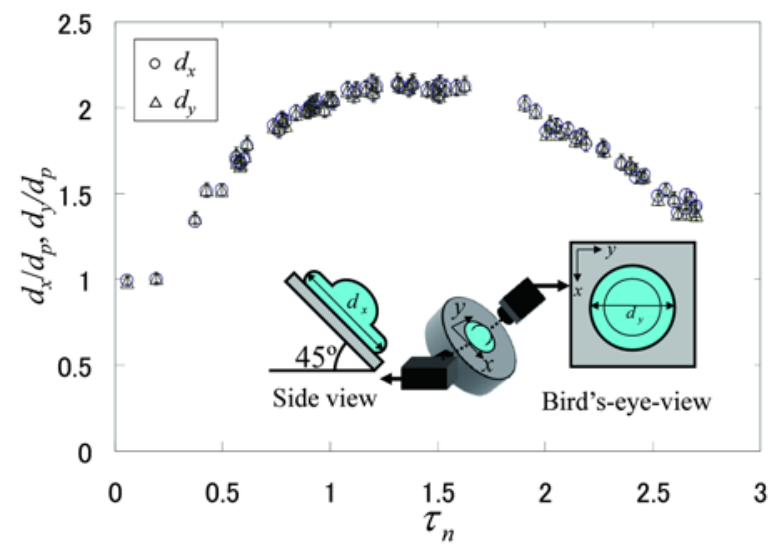

Fig11.tif 
(a)

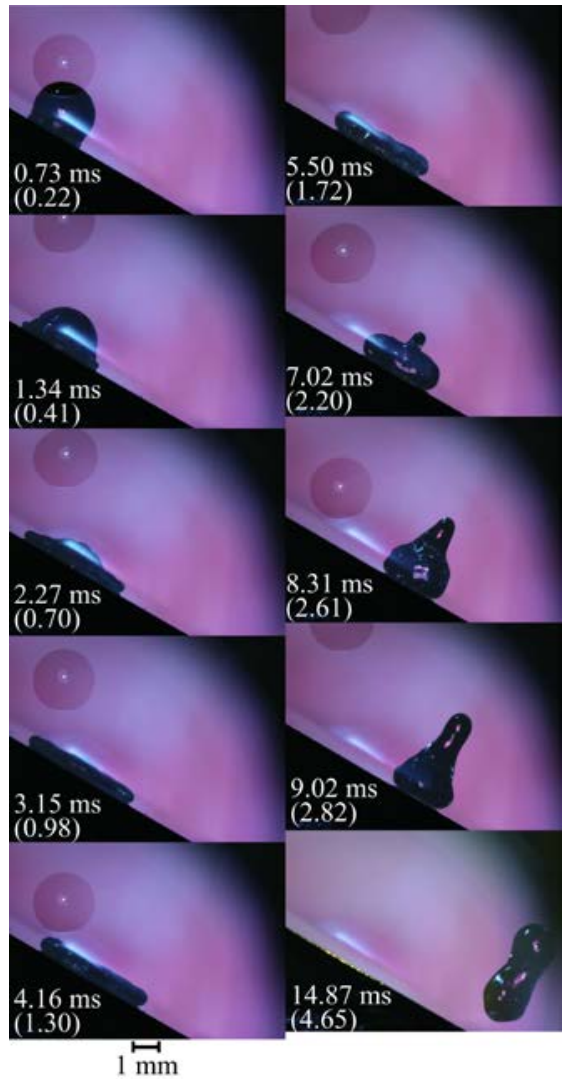

(b)

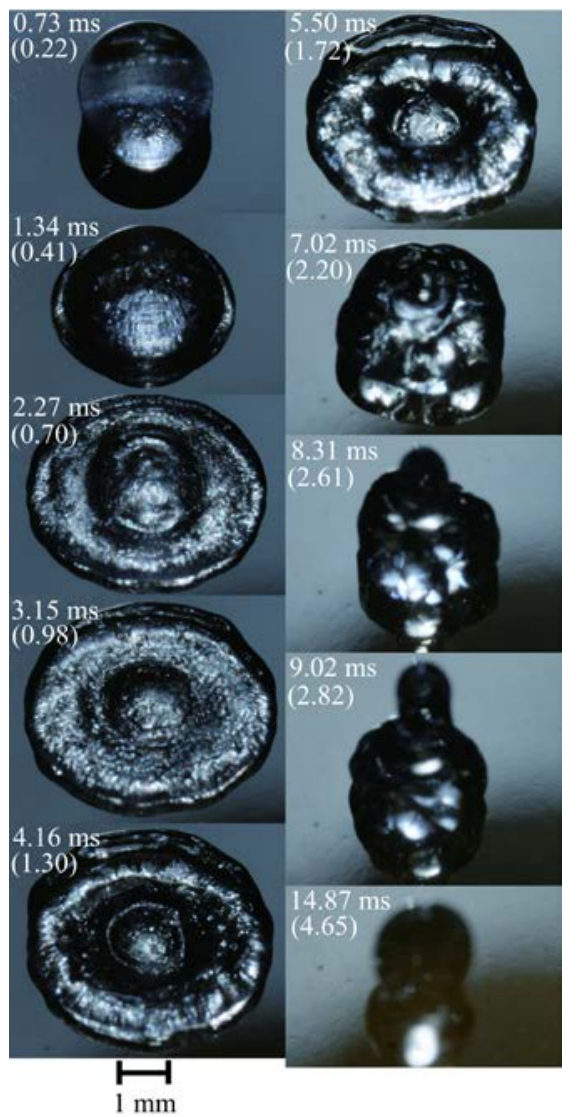

Fig12a.tif, fig12b.tif

Hitoshi Fujimoto, paper \# FE-11-1260 


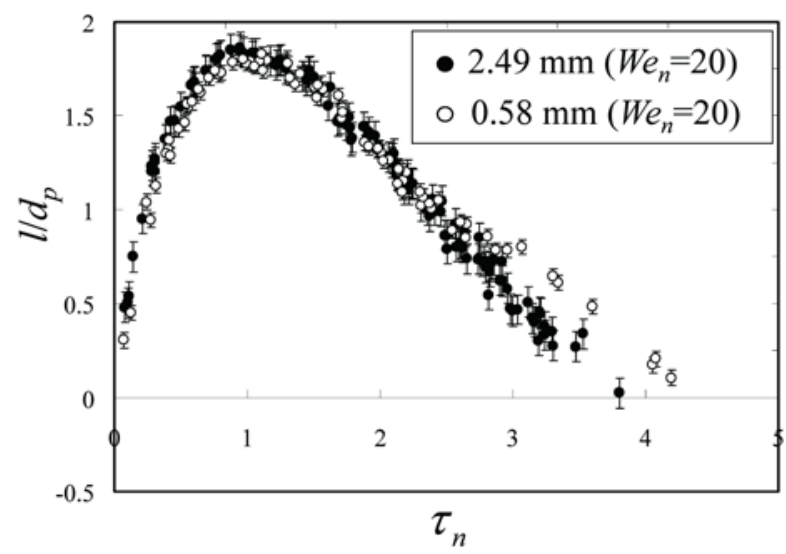

Fig13.tif 


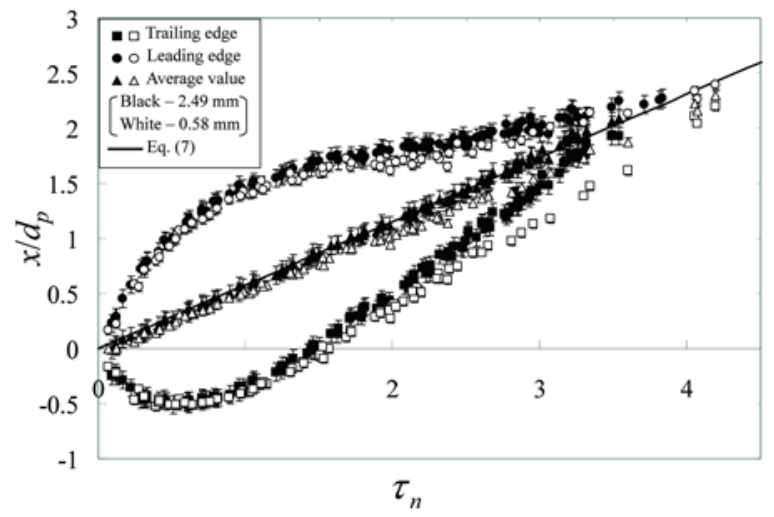

Fig14.tif 


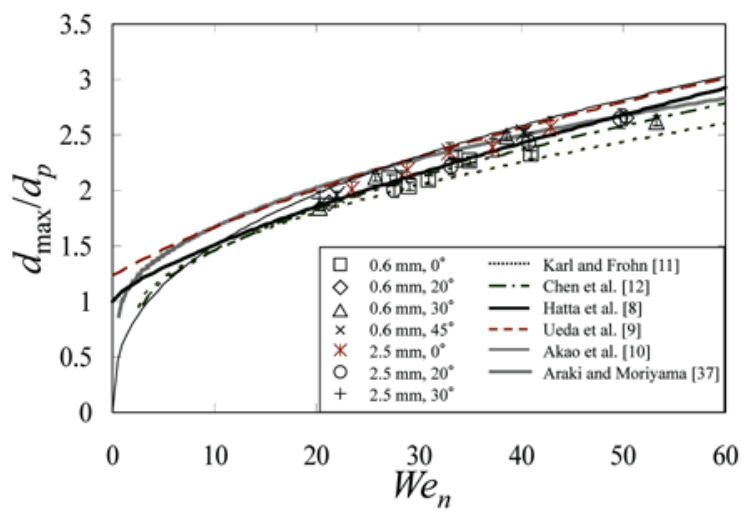

Fig15.tif 


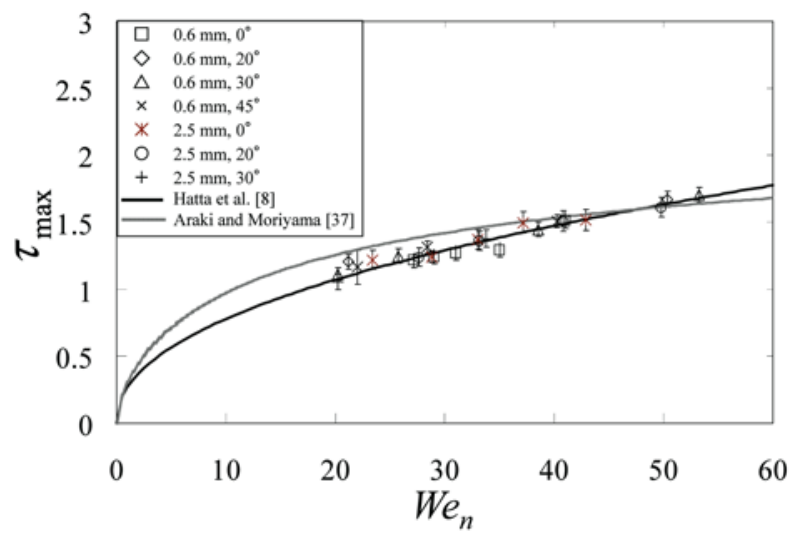

Fig16.tif 


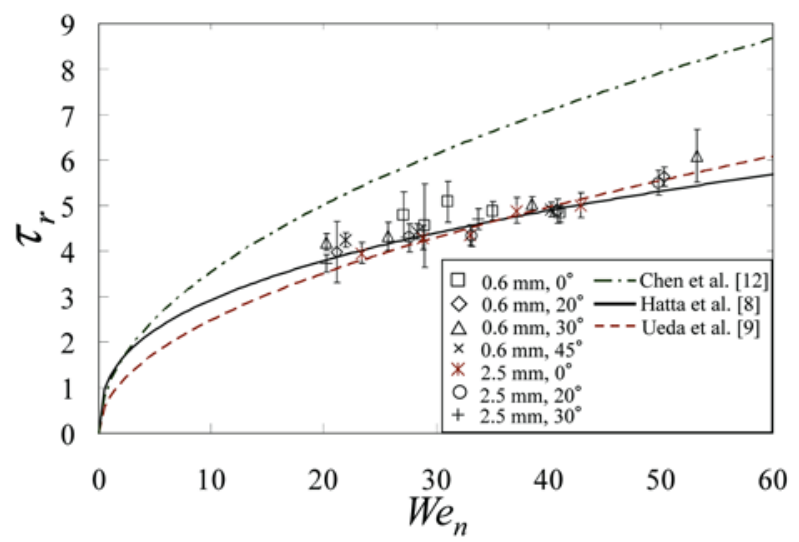

Fig17.tif 